\title{
APROXIMAÇÕES E AFASTAMENTOS PELO ALUNO DA EJA EAD NOS GÊNEROS DIGITAIS DISCURSIVOS COMO ESPAÇO DE INTERAÇÃO
}

\author{
Vilmar do Nascimento Rocba* \\ Diógenes Cândido de Lima ${ }^{* *}$
}

RESUMO: Entendemos a sala de aula presencial e online como espaços interacionais de discursivizações do sujeito. Este recorte tem como objetivo geral é mapear e categorizar comportamentos discursivos de um grupo de alunos do ensino médio do Sesi Unidade Sudoeste, da modalidade EaD, no sentido de visualizar ações e reações que se vinculam ao trabalho de todo e qualquer aluno, assim como aquelas que materializem especificidades do se aprender a distância. Especificamente, pretendemos encontrar indícios da interação do aluno no evento de interação didática em sala EaD. Justifica-se que o tema aqui abordado reveste-se de extrema relevância uma vez que notamos o surgimento de um sujeito discursivo, oriundo de um contexto industrial e que perpassa os muros da empresa para a sua formação intelectual em sala de aula, que possibilitam assim os letramentos desse sujeito, através de ferramentas tecnológicas disponíveis e desenvolvidas na contemporaneidade e que estão fortemente presentes nos diversos contextos da sociedade. A pesquisa se fundamenta, principalmente, nos escritos de Coscarelli (2002), Modl (2015a) e Paiva (2010). A metodologia é a qualitativa, no víes etnogrático. Já os procedimentos são entrada e observação no AVA e os sujeitos são os alunos do Ensino Médio EJA EaD do Sesi, locus da pesquisa. Os resultados mostram o afastamento dos sujeitos para o que chamamos de gêneros digitais discursivos como espaço de discrusivização dentro do AVA.

PALAVRAS-CHAVE: Educação a Distância; Gêneros Digitais Discursivos; Interação.

\section{Introdução}

Entendemos a sala de aula como mais um dos espaços interacionais de discursivizações do sujeito e que esses processos acontecem através das interações didáticas e das relações interacionais e interativas (MATENCIO, 2001; COELHO, 2011; MODL, 2015a). A partir desse paradigma, o nosso olhar se direciona para a sala de aula de Ensino Médio, a qual recebe alunos da Educação de Jovens e Adultos (EJA) na modalidade da Educação a Distância (EaD) do Serviço Social da Indústria (Sesi).

O campo de pesquisa da LA é complexo e sem muros, uma vez que ela se pauta em conceitos, teorias e procedimento de outras áreas do conhecimento e, por isso, a chamamos transdisciplinar. "Esse olhar transdisciplinar é necessário ao linguista aplicado, já que ele precisa cruzar teoricamente várias áreas, no sentido de entender as questões de pesquisa relacionadas à complexidade de fatores imbricados na linguagem e parametrizados em práticas sociais" AMARAL (2017, p. 25)

A motivação para a escolha dessa temática e do se fazer pesquisa se dá no sentido de que a sala de aula do Sesi recebe alunos que são, em sua maioria, trabalhadores da indústria

\footnotetext{
* Mestre em Letras: Cultura, Educação e Linguagens pela Universidade Estadual do Sudoeste da Bahia (Uesb). Professor de Língua Portuguesa e Professor-Referência no Serviço Social da Indústria.

** Doutor em Curriculum and Instruction (Estudos da Linguagem) pela Southern Illinois University, at Carbondale - EUA (SIUC). Professor pleno da Universidade Estadual do Sudoeste da Bahia (Uesb). Realizou estágio de pós-doutoral na Florida International University, em Miami, na área de Linguística Aplicada.
} 
e/ou os seus dependentes (FIEB, s.d.) que retornam à escola para a conclusão dos seus estudos, em nível médio, uma vez que a missão da instituição é "promover a qualidade de vida do trabalhador e de seus dependentes, com foco em educação, saúde e lazer, além de estimular a gestão socialmente responsável da empresa industrial.” (ibid.) Em suma, não se trata de um público convencional de uma instituição escolar regular e tradicional por entendermos que, com base na missão do Sesi, a instituição tende a atrair esse tipo específico de público, diferente da(s) escola(s) regulares públicas e privadas que têm o seu foco específico. Queremos dizer que a escola regular recebe qualquer aluno, oriundo de qualquer contexto, já o Sesi tem como foco no atendimento ao trabalhador da indústria e os seus dependentes. Por isso, acreditamos que esses sujeitos apresentam estratégias e representações didático-discursivas peculiares justamente por estarem inseridos no contexto industrial.

Notamos que, na contemporaneidade, inúmeras possibilidades de práticas pedagógicas consolidaram. Uma delas é a Educação a Distância, que se figura na flexibilização e no estímulo à autonomia dos alunos, além da promoção da proximidade entre sujeitos, através do ensino mediado por ferramentas tecnológicas em ambientes virtuais de aprendizagem (AVA). Em suma, há, de fato, um contato remoto entre sujeitos participantes do processo de escolarização, que podemos entender como territórios de discursivização, através dos gêneros digitais discursivos.

O tema aqui abordado reveste-se de extrema relevância uma vez que notamos o surgimento de um sujeito discursivo, oriundo de um contexto industrial e que perpassa os muros da empresa para a sua formação intelectual em sala de aula, que possibilitam assim os letramentos desse sujeito, através de ferramentas tecnológicas disponíveis e desenvolvidas na contemporaneidade e que estão fortemente presentes nos diversos contextos da sociedade. Ademais, este estudo dará subsídio científico para o Sesi e para todo o Sistema ' $\mathrm{S}$ '1 acerca de uma parcela de um grupo atendido por esse sistema, uma vez que pretendemos mapear e descobrir os padrões de comportamentos discursivos do público, o qual se fez em sujeitos da nossa pesquisa.

Isto posto, discorremos que o objetivo geral da pesquisa é mapear e categorizar comportamentos discursivos de um grupo de alunos do ensino médio do Sesi Unidade Sudoeste, da modalidade $\mathrm{EaD}$, no sentido de visualizar ações e reações que se vinculam ao trabalho de todo e qualquer aluno, assim como aquelas que materializem especificidades do se aprender

\footnotetext{
1 Termo que define o conjunto de organizações das entidades corporativas voltadas para o treinamento profissional, assistência social, consultoria, pesquisa e assistência técnica.
} 
a distância. Especificamente, pretendemos encontrar indícios da interação do aluno no evento de interação didática em sala de aula $\mathrm{EaD}$

Nesse contexto, a partir da percepção da diferenciação e distinção do público, questionamos então quais são os padrões de comportamento discursivos dos trabalhadores/alunos do Sesi Unidade Sudoeste e como se dão as relações interacionais e interativas desse sujeito no microcosmos sala de aula de Educação a Distância

A metodologia adotada na pesquisa é a qualitativa (FLICK, 2009; id., 2009b; ERICKSON, 2003) e de cunho etnográfico (MAGNANI, 2009; FLICK, 2009), visto que as observações são fundamentais nesse processo de entendimento no que diz respeito às interações didáticas nos eventos discursivos pesquisados. Os procedimentos são a entrada e observação no AVA. Os sujeitos são os alunos do Ensino Médio EJA/EaD do Sesi, Unidade Sudoeste, onde se deu o locus.

Por fim, os resultados nos mostram que é preciso que haja uma (re)ambientação do aluno para os ambientes digitais, bem como para a sua posição como aluno da $\mathrm{EaD}$.

\section{Letramento(s), Letramento Digital e Multiletramento(s)}

Quando se trata de ensino em aprendizagem através do uso de tecnologias digitais, seja ele em ambiente da Educação a Distância e na modalidade mediada por computador no ambiente online (BRAGA, 2007, p. 71), nos deparamos com o processo de Letramento Digital. Contudo, para que possamos discorrer acerca desse conceito, precisamos perpassar pelo letramento e lembrar das suas várias vertentes disponíveis para a pesquisa. Um olhar, portanto, para a sala de aula $\mathrm{EaD}$ requer um percurso, pelo que se discute, acerca do letramento.

Essa difícil tarefa de perambular pelos conceitos se pauta no nosso olhar para a sala de aula a distância do curso de ensino médio, no sentido de percebermos o processo de ensinar/aprender nos ambientes presencial e digital, observando as discursivizações dos sujeitos no evento de interação didática² (MATENCIO, 2001; COELHO, 2011; MODL³ 2015a) no interior desses ambientes.

Como já dissemos e já imergindo em um dos conceitos, não é uma tarefa simples construir a teorização sobre letramento(s), uma vez que se trata de um processo complexo,

\footnotetext{
${ }^{2}$ As autoras teorizam sobre a interação didática da/na sala de aula física, ou seja, aquela que ocorre na interação face a face. A nossa tarefa, com a pesquisa realizada, é justamente apontar aproximações e afastamentos do presencial e do virtual. O nosso apoio nas vozes das autoras é especificamente na/para a interação didática, no âmbito das relações interacionais (cf. seção 2.4), considerando que a relação professor/tutor e aluno acontece nos dois ambientes. Portanto, Matencio e Modl não produziram escritos tratando do ambiente online.

${ }^{3}$ Coelho e Modl tratam-se da mesma autora.
} 
interdisciplinar em que o sujeito se faz foco desse processo e há literatura em diversas matrizes teóricas. Por isso, precisamos assumir o nosso próprio posicionamento teórico acerca do tema.

Em relação ao que explicitamos, Assunção (2016, p. 23) nos elucida que

\begin{abstract}
A construção de um quadro teórico alicerçado em estudos e compreensões dos letramentos deve ser pautado por um ato contínuo de reflexões e, por isso, de chamamentos para desobvializações. Assumimos aqui que os letramentos efetivam-se em práticas e interações intersubjetivas orientadas por trocas linguageiras que figuram lugar genuíno de e para (re)construções identitárias marcadas por encontros e confrontos de negociação de sentidos entre os sujeitos investidos em posições ideológicas.
\end{abstract}

Entendemos, portanto, que o processo de Letramento(s) perpassa(m) o ambiente da sala de aula, não se limitando à alfabetização, e que requer do sujeito vários movimentos no sentido de não se balizar apenas pela educação formal, mas sim às suas vivências nos diversos contextos a que ele foi submetido no sentido de se identificar como um sujeito discursivo, ao longo dos seus perpasses por diversos contextos.

Um desses ambientes possibilitadores de discursivização do sujeito, portanto, é o Ambiente Virtual de Aprendizagem (AVA) por se tratar no qual requer do sujeito estudante o domínio do que envolve o letramento digital e as suas nuances.

Nessa vertente, a respeito do letramento digital, lembramos que dentro de um AVA, há a leitura hipertextual, e, portanto, o hipertexto é evidenciado nesse ambiente. O hipertexto, por sua vez, é um texto que traz conexões, chamadas links, com outros textos que, por sua vez, se conectam a outros, e assim por diante, formando uma grande rede de textos. (COSCARELLI, 2002, p. 71).

Por conseguinte, os conceitos de navegação diretamente ligados à leitura de hipertexto aparecem fundamentados em Lévy (1993, p. 57). O autor trata os hipertextos como dispositivos lógicos, classificatórios e espaciais sustentados uns nos outros no interior de uma estrutura administravelmente sistemática, de acesso não linear e seletivo e exemplifica usando as páginas de títulos, sumários notas e referências cruzadas.

Quando consideramos os ambientes digitais, assim como o AVA, todo 'texto' continua a ser uma produção linguística dotada de significado em situação de comunicação entre duas partes (quem escreve e quem lê), porém, o espaço de escrita e leitura passa a ser outro bem diferente do papel. Esse novo espaço interfere no modo como o texto é lido, recebido, interpretado e compreendido. Portanto, as relações de interlocução apontam para características mais dinâmicas e complexas, já que esses novos 'textos' pedem uma posição mais ativa por parte do leitor em relação aos impressos, visto que o ambiente virtual, por assim dizer, 
permite ao leitor contemplar infinitas informações por se evidenciar o dinamismo e estar perpetuamente em movimento. (COSTA VAL, 2004, p.3).

Coscarelli e Ribeiro (s.d.), no Glossário Ceale, elucidam que o(s) conceito(s) de letramento(s) está(ão) focado(s) nos textos impressos e, portanto:

\begin{abstract}
Letramento digital diz respeito às práticas sociais de leitura e produção de textos em ambientes digitais, isto é, ao uso de textos em ambientes propiciados pelo computador ou por dispositivos móveis, tais como celulares e tablets, em plataformas como e-mails, redes sociais na web, entre outras. (grifos nossos)
\end{abstract}

No ambiente da internet, o universo de informações é estratosférico e, portanto, cabe ao leitor digital saber selecionar aquilo que realmente é importante e direcionar a sua pesquisa de forma certeira e satisfatória. Ainda assim, é difícil, como nos conceitos de letramentos, estabelecer um único parâmetro para tratamento do Letramento Digital. Assim, as autoras ainda completam que

ser letrado digital implica saber se comunicar em diferentes situações, com propósitos variados, nesses ambientes, para fins pessoais ou profissionais. Uma situação seria a troca eletrônica de mensagens, via e-mail, sms, WhatsApp. A busca de informações na internet também implica saber encontrar textos e compreendêlos, o que pressupõe selecionar as informações pertinentes e avaliar sua credibilidade. (id., grifos nossos)

Logo, assumimos que o letramento digital está diretamente ligado aos conceitos de letramento(s), visto que o sujeito é o alvo do processo e (m) que as tecnologias digitais permitem que vá além do ambiente físico, podendo posicionar-se discursivamente neste ambiente, uma vez que as suas representações e práticas sociais podem ser publicizadas no ambiente digital. Retomando à leitura hipertextual e com foco no nosso escrito em que tratamos da sala de aula, Rojo nos explica que a escola não deve limitar o aluno apenas ao ambiente impresso e tradicional, ao qual a instituição escolar está pautada há centenas de anos. A autora também alerta para a urgência que se faz necessária para a introdução do aluno na vida contemporânea dentro do ambiente escolar (ROJO, 2017, p. 4). Portanto, passemos agora, através do gerenciamento da voz da autora com a nossa voz, tratar de multiletramento. Explicamos, contudo, que os escritos não descartam as práticas de letramento(s) que envolvem o conceito. Multiletramentos, portanto, serão:

[...] as práticas de trato com os textos multimodais ou multissemióticos contemporâneos - majoritariamente digitais, mas também impressos -, que incluem procedimentos (como gestos para ler, por exemplo) e capacidades de leitura e produção que vão muito além da compreensão e produção de textos escritos, pois 
incorporam a leitura e (re)produção de imagens e fotos, diagramas, gráficos e infográficos, vídeos, áudio etc. (ROJO, 2017, p. 4, nota de rodapé)

Adiante, e de acordo com os nossos entendimentos, os multiletramentos não tem foco na tecnologia e sim no sujeito. A tecnologia não faz nada sozinha, por isso, é necessário que haja a interferência desse sujeito no seu manuseio e na promoção da interatividade, "isto é uma nova maneira de ver e de ser no mundo contemporâneo, que prioriza a interatividade, a colaboração e a (re)distribuição do conhecimento, ao invés da hierarquia, da autoria e da posse controlada e vigiada do conhecimento por diversas agências, como a escola, as editoras e a universidade.” (ROJO, 2017, p. 4, nota de rodapé). Isso significa que há desobivialização de que a tecnologia promove o letramento do sujeito. Trata-se, portanto, de ferramenta, essencial na contemporaneidade, para promoção da autonomia do sujeito e para a construção de práticas colaborativas e transformadoras online. (BRAGA, 2007, p. 71; LEMOS, 2016).

Quanto à cultura digital, a qual entendemos que está se inserindo na cultura escolar através dos multiletramentos, citamos que "a quarta revolução da escrita, como a chama Chartier (1997), a cultura digital, põe por terra todo o edifício de práticas letradas cultuadas e perpetuadas pela escola." (ROJO, 2017, p. 7). Nesse ambiente, portanto, o sujeito deixará a sua passividade de lado (LEMOS, 2016), assumindo o papel protagonista do processo da sua própria evolução.

\section{Ambientes Virtuais de Aprendizagem (AVA): Práticas e processos de ensino e apren- dizagem no ambiente digital}

Como já discorremos anteriormente, em tempos de busca por formas mais interativas de aprendizagem, podemos evidenciar nos AVA maneiras de ensino e aprendizagem que se fazem colaborativas". "Essas novas práticas devem ser propostas de forma articulada, estrutural e funcionalmente enredadas com a realidade [...]". (MORAES, 2008 apud SILVA, 2013, p. 12). Logo, um AVA deve ser estruturado de forma que os partícipes deste ambiente consigam interagir com agilidade, facilidade e que traga uma resposta à sua realidade

Esses indivíduos devem ser capazes de associar o virtual com o físico, visto que o aluno conhece bem o ambiente físico da escola tradicional ${ }^{5}$ e essa nova prática traz consigo o desafio de entrelaçar os dois ambientes para que se tenha o reconhecimento do processo que

\footnotetext{
${ }^{4}$ Assumimos colaboração como processo colaborativo de aprendizagem, em consonância com Braga (2007, p. 70), a qual explica que "os pares processam trocas significativas com o parceiro tanto no sentido de prover informações, ajuda e correções quanto no sentido de usufruir as idéias (sic) do parceiro."

5 Termo adotado por Modl nos seus diversos trabalhos sobre interação didática na/da sala de aula física.
} 
está ali disposto. Por isso, Silva (2013, p.12) ainda discorre que "elas [as novas práticas] devem ser pensadas como uma teia, uma rede de saberes e práticas, que relacionam indivíduo e seu meio". E é assim que pensamos a nossa pesquisa: apontamentos da escola tradicional (MODL, 2015a) atrelados à essa nossa nova prática discutida por Silva (2013) e por Soares (2011 e 2014), por exemplo.

Portanto, e de forma elucidativa, sem perder a objetividade do texto, citamos que "os Ambientes Virtuais de Aprendizagem são plataformas educacionais que têm sido amplamente utilizados por instituições de ensino superior, em cursos de extensão, graduação e pósgraduação, tanto no que se refere à educação a distância, como também à educação presencial." (SOARES, 2014, p. 67). Ainda que Soares, antes citada, aborde um contexto em nível superior, o nosso olhar está direcionado para a modalidade do ensino médio, que faz uso do AVA no seu processo de escolarização do sujeito. Um olhar para o desenho de AVA, Rojo (2017, p.4) explica que esses ambientes "apresentam também diagramas, tabelas, campos, formulários, boxes (como e-mails, torpedos e agendas) ou fotos, imagens, mapas, plantas, vídeos, animações, sons, música, fala e uma multidão de outras linguagens.”

Assim, por um lado, o que difere um AVA de um ambiente físico é o estímulo no aluno, em processo de escolarização, para que a passividade seja minimizada ao máximo (LEMOS, 2016), uma vez que esse sujeito, frequentante de um AVA, precisa mostrar-se inteiramente ativo. Logo, o objetivo das relações nesses ambientes é "transformar sujeitos passivos em cidadãos ativos e críticos, por meio de uma postura de mediador [...], procurando, para isso, aliar a realidade virtual à educação" (OLIVEIRA NETTO, 2005, p.22 apud SILVA, 2013, p.12).

Tratando-se, então, de AVA, lembramos que esses ambientes foram idealizados, em um primeiro momento, para atender a cursos a distância. Contudo, as plataformas digitais podem ser usadas, também, segundo experiências feitas e relatadas por Pereira (2007, apud SILVA, 2013 p. 59) como instrumento de complementação de aulas presenciais, dado o seu valor como instrumento de ampliação dos saberes. Ainda assim, "faz-se necessário sublinhar o fato de serem novidade, o que geralmente requer um processo de adaptação" (SOUZA, 2011, p. 68).

\section{Gêneros digitais discursivos contextualizados em AVA como espaços de interação}

Podemos chamar de gêneros digitais discursivos dentro de um AVA, uma vez que esses espaços se (re)constroem na discursivização do sujeito dentro da plataforma, pois “a natureza fluida desses gêneros os apresenta não apenas como artefatos, mas como meios de 
participação em um ato comunicativo" (SOUZA, 2011, p. 63). Para que a ideia do título da nossa seção não pareça estranho, a autora nos elucida, fundamentada em Araújo e BiasiRodrigues (2005, p. 13), quando cita que os autores defendem que "o estudo das práticas discursivas ambientadas na $W e b$; ou seja, dos gêneros discursivos que aí emergem, torna-se imperativo dentro da academia" (loc. cit.). Mais interessante e instigante é a abordagem e nominação do AVA como uma comunidade discursiva de aprendizagem (SOUZA, 2011, p. 63), que corroborando com a autora, assumimos como definição cara e clara ao ambiente em que propomos o nossos estudos, afinal, se o processo de interação e escolarização do sujeito acontece no interior de um AVA, ela somente se (re)afirma pela discursivização ${ }^{6-7}$ do sujeito ali inserido (PAIVA, 2010; MODL, 2015a).

Retomada a adaptabilidade que o(s) sujeito(s) inseridos no contexto especificamente do AVA, como comunidade discursiva, experimentam, vemos que a essa característica se faz como primordial para a entrada e permanência do partícipe dentro do ambiente. Reforçamos a nossa escolha lexical ${ }^{8}$ do item permanência, pois o sujeito não deve apenas entrar, mas sim continuar inserido no processo, que na nossa pesquisa se configura com o ensino médio a distância. Vejamos:

\begin{abstract}
À luz da complexidade, o fato de a comunidade discursiva ter, a princípio, (6) um nível de membros com um grau apropriado de conteúdo e conhecimento relevantes, (1) um conjunto de objetivos amplamente acordados e (2) mecanismos de comunicação entre seus membros está relacionado não apenas às condições iniciais a partir das quais a comunidade é formada, mas, ainda, ao processo de adaptabilidade ao longo do tempo no qual a comunidade perdura. (SOUZA, 2011, p. 69)
\end{abstract}

A autora nos explica que os sujeitos dentro de um AVA têm objetivos em comum e que esses objetivos são fatores primordiais para a criação e (sobre)vivência dessa comunidade discursiva. A adaptação do sujeito ao ambiente e ao processo indicam, portanto, a sua continuidade, uma vez que suponhamos que ela garantirá a comunicação multidirecional dos sujeitos durante os eventos de interação didática (MATENCIO, 2001; MODL, 2015a) no ambiente.

\title{
E-mail
}

\footnotetext{
${ }^{6}$ Paiva (2010) trata de interação. Atualizamos o conceito para discursivização, uma vez que a interação é constituída de discursivização (cf. MODL, 2015a).

${ }^{7}$ Modl (2015a) trata da discursivização em ambiente físico. Apoiamo-nos na voz da autora por entendermos que o gênero digital discursivo é espaço de discursivização e interação.

8 Termo que utilizamos para demonstrar a nossa eleição de item(ns) dentro do vasto léxico da Língua Portuguesa Brasileira, código verbal em que este trabalho é escrito.
} 
Trabalhar com a conceituação e definição do que chamamos, aqui, de gênero discursivo digital e-mail não é tarefa fácil, visto que esse espaço de interação (SOARES, 2011) já foi visto como revolucionário e substituto da tão consagrada carta. Hoje, já não é bem assim, há opiniões empíricas que já nos deparamos que afirmam que o e-mail é "coisa de gente velha". Ao pensarmos no e-mail como ferramenta de um AVA, ele se fará em um item essencial para que a interação aconteça.

Paiva (2004, p. 77-78) citada por Souza (2011, p. 75-76) trata o e-mail como:

\begin{abstract}
um gênero eletrônico escrito, com características típicas de memorando, bilhete, carta, conversa face a face e telefônica, cuja representação adquire ora a forma de monólogo ora de diálogo e que se distingue de outros tipos de mensagens devido a características bastante peculiares de seu meio de transmissão, em especial a velocidade e a assincronia na comunicação entre usuários de computadores.
\end{abstract}

Acreditamos que essa seja uma definição bem esclarecedora e essencial do e-mail, mesmo se considerarmos as novas ferramentas de interação que surgiram depois do momento em que ela foi escrita, mesmo porque o computador não é mais o único equipamento que abarca as ferramentas de interação no ambiente online, visto que os tablets e os smartphones são exemplos desses equipamentos e estão acessíveis à maioria da população.

Fica claro, então, o aspecto assíncrono no e-mail (PRIMO, 2000), ou seja, a interação pode acontecer a qualquer momento sem que haja a interlocução imediata no ambiente e não há como esgotarmos a lista dos assuntos que podem ser discutidos através dele. Vejamos:

Podemos compreender que o email faz parte de um grupo de sistemas discursivos complexos que são os gêneros; portanto, não podemos minimizar seu impacto nas diversas comunidades discursivas, especialmente por ser uma ferramenta de in(ex)clusão social; ou seja, por meio de mensagens enviadas via email, podemos nos informar sobre oportunidades acadêmicas e mercadológicas, como propostas de bolsas de estudos ou editais para concursos públicos. (SOUZA, 2011, p.75)

Um aspecto bem interessante e que chama a atenção para o direcionamento do nosso olhar como pesquisador é o fato de Souza (2011) tratar da inclusão e exclusão social desse espaço de interação.

\title{
Chat
}

Diferente do e-mail, o chat mostra-se como um gênero digital discursivo síncrono (PRIMO, 2000), uma vez que permite que a interação aconteça de forma simultânea. No caso da nossa pesquisa, analisamos a interação no evento interacional dentro de um AVA. "Partindo da pluralidade das funções sociais dos chats e das práticas discursivas síncronas que 
são mais atraentes na Internet, a pesquisa discute a natureza hipertextual do gênero chat aberto." (SOUZA, 2011, p.77). Os estudos mostram que a linguagem dentro desse espaço de interação será mais leve, sem tanta formalidade e que alguns tópicos da gramática normativa não serão obedecidos (loc. cit.), o que caracteriza um afastamento em relação ao e-mail.

Outro afastamento detectado se faz no sentido de que os interlocutores necessitam estar $\log \operatorname{dados}^{9}$ no ambiente para que a interação aconteça. De fato, não há como haver interação no chat sem que mais de um usuário esteja [dentro] do sistema no momento da interação.

\section{Fórum}

Assim como o e-mail, porém, afastado do chat, o fórum é um gênero digital assíncrono (PRIMO, 2000), visto que os participantes podem discursivizar a qualquer tempo, sem que haja perda daquilo que está sendo tratado. "Por acontecer de forma assíncrona, alunos e professores têm a possibilidade de administrar sua participação conforme conveniência de seu próprio tempo. Não há a necessidade de que todos estejam conectados ao mesmo tempo para que uma discussão ocorra." (SOARES, 2011, p. 42). Em suma, as discussões online, no fórum, podem acontecer a qualquer momento, em um determinado ínterim.

Souza (2011, p. 76), além de elucidar que as produções discursivas ali acontecem, em decorrência da interação dos sujeitos, nos explica:

\footnotetext{
Os fóruns eletrônicos usualmente têm a função de dar suporte a uma comunidade discursiva. Os fóruns on-line, por exemplo, caracterizam-se especialmente pela relação dialógica que acompanha os variados discursos produzidos por seus participantes, e a interação destes difere da interação oral pela possibilidade de se interagir com mensagens produzidas em tempos distintos. (grifo nosso)
}

Os dizeres da autora mostram que o aporte dado por esse gênero digital é importante para as comunidades de práticas (WENGER, 1998), já discutidas neste trabalho, formadas dentro de um AVA, além de ser efetivamente um espaço de diálogo e de interação.

\section{Percurso Metodológico}

\section{A pesquisa qualitativa}

\footnotetext{
${ }^{9}$ Lexicalização que ocorre com a junção do radical log, da palavra login, do inglês, que significa entrar e o sufixo ado que indica particípio passado no português. Em suma, o termo logado significa que o usuário deve estar acessando o AVA no momento da interação.
} 
A pesquisa aqui descrita é qualitativa, haja vista tratar-se na análise das relações dos sujeitos dentro de um determinado contexto. Nesse caso, o nosso olhar é para a os eventos ocorridos na sala de aula e nas interações dentro de um AVA.

A ideia central da pesquisa qualitativa está fundamentada na seguinte perspectiva:

\begin{abstract}
Os aspectos essenciais da pesquisa qualitativa consistem na escolha adequada de métodos e teorias convenientes; no reconhecimento e na análise de diferentes perspectivas; nas reflexões dos pesquisadores a respeito de suas pesquisas como parte do processo de produção de conhecimento; e na variedade de abordagens e métodos" (FLICK, 2009, p. 23)
\end{abstract}

É também de cunho etnográfico, visto que houve a observação dos sujeitos e das suas relações. Sobre esse viés etnográfico da pesquisa, corroboramos com Magnani (2009, p.133): “o ponto de partida é que não se pode separar etnografia nem das escolhas teóricas no interior da disciplina, nem da particularidade dos objetos de estudo que impõem estratégias de aproximação com a população estudada e no trato com os interlocutores".

\title{
Locus da pesquisa
}

Nesse contexto, explicamos que o Sesi é uma organização de direito privado sem fins lucrativos e juntamente com a $\operatorname{Cieb}^{10}$, o Senai ${ }^{11}$, o IEL ${ }^{12}$ e outras instituições integram o Sistema 'S'. No estado da Bahia, está diretamente subordinada à Fieb ${ }^{13}$.

O sujeito que atinge a maioridade e que não teve a oportunidade de concluir os seus estudos em idade escola, quando o quer fazer é recebido pela EJA. Na nossa pesquisa, que aqui publicizamos, focamos o nosso olhar para os padrões de comportamento desse aluno, que retoma os seus estudos por um desejo ou necessidade de conclui-los em nível da educação básica ${ }^{14}$.

Mais especificamente, o nosso sujeito de pesquisa é oriundo da indústria, ou seja, é um trabalhador que cumpre a sua jornada de trabalho diária e que em suas horas de folga, dedicase aos estudos.

\section{Sujeitos da pesquisa}

\footnotetext{
${ }^{10}$ Centro das Indústrias do Estado da Bahia.

11 Serviço Nacional de Aprendizagem Industrial.

12 Instituto Euvaldo Lodi.

${ }^{13}$ Federação das Indústrias do Estado da Bahia

${ }^{14}$ Educação básica engloba os ensinos fundamentais e médio. A conclusão do ensino média habilita o aluno a ter acesso ao ensino superior.
} 
O nosso universo de pesquisa se pauta no $3^{\circ}$ Ano do ensino médio da EJA, na modalidade EaD do Sesi, da Unidade Sudoeste, estabelecida em Vitória da Conquista/BA. No ensino médio são 187 alunos matriculados, especificamente no $3^{\circ}$ ano identificamos 77 sujeitos, divididos em duas turmas, as quais, e de acordo com a cultura escolar, as denominamos de A e B.

Além dos alunos, o tutor da disciplina figura-se também como sujeito de pesquisa, uma vez que conduz a disciplina nas aulas presenciais nos diferentes ambientes que ela acontece e no AVA. O coordenador pedagógico também é um sujeito de pesquisa, pois é peça importante no processo, uma vez que é dele a visão holística do certame de ensino-aprendizagem dentro da Unidade Sudoeste.

\section{A nossa entrada e observação no/do AVA}

No sentido de atingirmos um dos objetivos da nossa pesquisa, o qual se pauta nas ações e reações que se vinculem ao trabalho de todo e qualquer aluno e que se materializem especificidades do se aprender a distância (LÉVY, 1993; SANTAELLA, 2017; ROJO, 2017), fundamentado nos letramentos, nos multiletramentos, na multimodalidade e na hipertextualidade (COSCARELLI, 2002; BRAGA, 2007; PAIVA 2013; SOARES, 2011; id. 2014; ASSUNÇÃO 2016), foi necessária a nossa entrada e observação no/do AVA, utilizado pelo Sesi, o qual nominamos como LMS (Learning Management System).

Para que pudéssemos efetivar o nosso olhar para o LMS recebemos, da coordenação pedagógica, um login e uma senha de acesso ao sistema. Como todo e qualquer AVA, o LMS pode ser acessado de qualquer computador com acesso à internet. $\mathrm{O}$ ambiente também pode ser acessado de um smartphone ou de um tablet, desde que, assim como no computador, tenha disponível uma rede de internet. O nosso olhar foi especificamente para os gêneros digitais discursivos: chat, e-mail e fórum.

\section{Interação no gênero digital discursivo chat.}

Para a análise dos eventos de interação dentro da plataforma AVA, elegemos, três do que chamamos gêneros digitais discursivos: chat, e-mail e fórum, lugares onde acontecem essas interações no ambiente online. Com a nossa entrada no ambiente, identificamos sete eventos, ou tentativas, de interação. Lembramos que os nomes são fictícios para preservarmos a identidade dos sujeitos de pesquisa.

Quadro 01: Evento 1 de interação 
Oi boa noite eu fiz uma prova hoje a tarde queria saber se já tenho a pontuação meu nome é Gustavo Torres

Tutor:

Boa noite!

Qual o seu polo?

Fonte: Dados da pesquisa

Quadro 02: Evento 2 de interação

\section{Tutor:}

Olá Guilhermino, tudo bom?

Como estão os estudos da plataforma?

Alguma dificuldade?

Aluno:

Boa tarde maria

estou com uma certa dificuldade em entender tem uma mensagem quando verifico o relatório de desempenho que diz "O usuário ainda não passou nesta tarefa com sucesso."

o que quer dizer e o que devo fazer para concluir uma vez que já estudei todo o material deste modulo?

\section{Tutor:}

Certo, creio que entendi a sua dúvida.

Algumas "Partes" da plataforma, gera uma porcentagem em cima de um acesso. Porém nem sempre o mesmo é registrado, devido conexão ou alguns erros familiares.

Mas pode ficar tranquilo, que acompanhamos o seu desempenho especificamente, nas abas de conclusão de tarefas. E a mesma, nos dá um relatório mais especifico.

\section{Aluno:}

pois é inclusive a nossa internet aqui no interior da Bahia dificultou bastante

Tutor:

Algo mais que possa ajudar?

Aluno:

não obrigado

no mais esta tudo certo excelente material

Tutor:

Que bom! Fico feliz em poder ajudar!

Fonte: Dados da pesquisa

Quadro 03: Evento 3 de interação

\section{Tutor:}

Olá Francisco, tudo bom?

Como estão os estudos da plataforma?

Alguma dificuldade?

Aluno:

Olá, está tudo bem obrigado 
No evento 1, observamos que a interação se inicia, porém, não é continuada. Há uma interrupção por conta de o aluno não interagir mais com o tutor. Ele faz uma pergunta e o tutor responde com outra questão e, logo, a interação é cessada. Notamos que não há o questionamento sobre o conteúdo da disciplina, mas sim a respeito de questões técnicas do curso.

No evento 2, a interação é iniciada pelo tutor e não pelo aluno, ou seja, o sujeito que parece ter mais intimidade com a ferramenta é quem estimula a interação. Novamente, a dúvida não é em relação ao que se estuda, mas às questões técnicas da plataforma, o que mostra o distanciamento do aluno no uso da ferramenta. $\mathrm{O}$ aluno elogia o material, o que nos mostra a relação interativa coma tecnologia, que está além dos gêneros digitais discursivos.

No evento 3, a interação é novamente iniciada pelo tutor e ele demonstra se interessar pelo desempenho do aluno dentro da plataforma. A interação acontece apenas uma única vez quando o aluno responde positivamente sobre o seu caminhar no AVA. Temos, então, o cessamento da interação e nada mais é tratado.

Nos três eventos observados, identificamos a sincronia do gênero digital discursivo chat (cf. PRIMO, 2000; ROCHA; LIMA, 2017). Identificamos também que os recursos imagéticos e pictórios não foram utilizados por nenhuma dos interlocutores no evento de interação (SOUZA, 2011, p. 77). A linguagem é leve e sem formalidades (SOUZA, 2011).

Dos três eventos pesquisados, notamos que apenas o evento 2 se estende e acontece de forma a ocorrer a interação com mais solidez, visto o engajamento dos sujeitos no momento da interação (KERBRAT-ORECCHIONI, 2006), contudo nos demais eventos, a interação é tímida ou não é materiazalida, visto o não engajamento dos sujeitos.

\section{Interação no gênero digital discursivo e-mail:}

Quadro 04: Evento 4 de interação

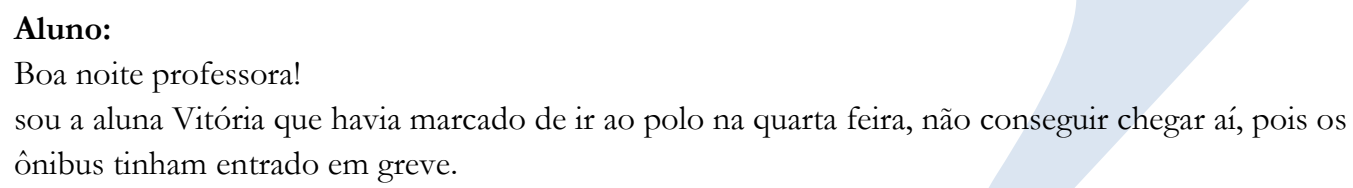

Fonte: Dados da pesquisa

Quadro 05: Evento 5 de interação

Aluno:

prof. Maria vc não me ligou pra falar se eu passei na sua matéria. Estou aflita pra saber. bjos. (77) 11111 1111. obrigada. 
No evento 4, o aluno inicia uma tentativa de interação no sentido de posicionar a professora sobre a sua ausência em algum evento marcado presencialmente no polo, contudo, não há a interação, visto que a professora não responde à mensagem do aluno.

No evento 5, a tentativa de interação também é iniciada pelo aluno. Ele quer saber sobre a sua aprovação no componente curricular e usa o gênero para realizar o questionário, mas solicita que a resposta seja oralizada, ignorando a possibilidade de se realizar a interação ali mesmo no gênero, que por sua vez está no interior do AVA. O tutor atende ao anseio do aluno e telefona para ele.

Notamos, portanto que os sujeitos discursivos aluno e tutor se distanciam do uso do gênero digital discursivo e-mail e praticamente desprezam este tipo de interação (PAIVA, 2010; SOUZA, 2011; MODL, 2015a). Entendemos que a possibilidade de assincronia oferecida pelo gênero (PRIMO, 2000; ROCHA; LIMA, 2017) e, logo, a flexibilização da interação, o que facilitaria o processo é tido como fator de distanciamento dos sujeitos.

Os aspectos de formalidade na linguagem, comum ao e-mail, não foram levados em consideração no momento da escrita e, por isso, percebemos mais um elemento de distanciamento do discursivizar do sujeito com o gênero, o que nos alerta para os fatores de in(ex)clusão social, conforme advoga Souza (2011).

Igualmente ao que notamos nas análises do gênero digital discursivo chat, o engajamento dos sujeitos (KERBRAT-ORECCHIONI, 2006) não acontece para que haja interação.

\section{Interação no gênero digital discursivo fórum:}

Quadro 06: Evento 6 de interação

Fórum livre - Este espaço é de uso livre. Aqui você poderá conversar com seus companheiros do curso, trocar informações, disseminar referências e indicações de leitura.

\section{Aluno 1:}

ola profesoura bom dia eu sou rodrigo de vitoria da conquista bahia tenho

Aluno 2:

oi turma to doidinho pra começar logo os estudos

Fonte: Dados da pesquisa

Quadro 07: Evento 7 de interação

Fórum de dúvidas - Este espaço é destinado para que enviem as suas dúvidas sobre os objetos de aprendizagem, uso do LMS e o que necessitarem. 


\section{Aluno 3:}

Ola, Bom dia pessoal !!

Fonte: Dados da pesquisa

No evento 6, percebemos se tratar de um fórum livre, ou seja, os alunos podem comentar o que quiser dentro desse gênero digital discursivo. Já o evento 7, mostra que tratase de um fórum específico para dúvidas, ou seja, é uma ferramenta importante para auxílio da disciplina, em curso, um espaço que os sujeitos discursivos alunos podem discursivizar as suas inquietações sobre os assuntos estudos.

Ambos eventos, dentro do ambiente fórum, são fortes motivadores para o estabelecimento de uma comunidade de prática, como defende Wenger (1998), por se tratar de espaço importante de interação, e ainda se constituem em lugar de interação (SOARES, 2011), contudo, a nossa coleta de dados mostram que o gênero é inutilizado para esses propósitos e que, novamente, não há o devido engajamento dos sujeitos (KERBRAT-ORECCHIONI, 2006) para que a interação aconteça, uma vez que os gênero digital discursivo fórum é dinâmico a auxilia no posicionar e no discursivizar do sujeito e no seu se entender como representação de um grupo (BRAGA, 2007).

Após analisarmos todos os eventos que aqui descrevemos, percebemos que há o uso da palavra como revelador de traços culturais e de projeção dos sujeitos discursivos aluno e tutor (MODL, 2015a), dentro de uma prática discursiva no ambiente web (SOUZA, 2011). As relações interacionais ocorridas entre professor, no nosso caso tutor, e aluno (MATENCIO, 2001; COELHO, 2011, MODL, 2015a) são evidentes nos eventos pesquisados, contudo, não em uma perspectiva da oralidade, como advogam as autoras, mas na interação ocorrida nos gêneros digitais discursivos dentro do AVA.

Ademais, observamos a fragilidade dos gêneros digitais discursivos no AVA pesquisado, uma vez que os seus usos são tímidos e há pouca ou nenhuma interação. Diante disso, entendemos que essas ferramentas poderiam ser melhor exploradas pelos sujeitos ali inseridos, tendo em vista a riqueza de possibilidades que apontamos em toda a nossa pesquisa.

Finalizamos essas análises com a voz de Bruner (1996, p. 98) quando diz que as pessoas precisam ser capacitadas para a utilização e operação daquilo que lhe é potencial e no uso dos instrumentos que a permeiam. Portanto, entendemos que é esse engajamento que os sujeitos tutor e coordenadora pedagógico precisam se apoiar para que os sujeitos alunos inseridos nesse processo de escolarização possam ser estimulados a discursivizar não apenas 
na interação face a face, mas também utilizando-se do gênero digital discursivo, os quais são lugares importantes de discursivização e que são aportados pela tecnologia.

\section{Considerações Finais}

Conseguimos perceber o (re)posicionamento dos sujeitos, oriundo do ato de frequentar o ambiente escolar (cf. MATENCIO, 2001; COELHO, 2011; MODL, 2015a), bem como as suas novas representações sociais dentro do grupo, como sujeito discursivo. Identificamos traços da cultura escolar (MODL e BIAVATI, 2016), uma vez que os sujeitos da pesquisa conseguem identificar e discursivizam os afastamentos e aproximações do evento pesquisado com a escolar regular tradicional.

A EaD, como tantos autores respeitados a tratam, se faz em uma modalidade que permite flexibilidade e autonomia ao sujeito discursivo aluno, no que tange o seu percurso no processo de escolarização. Falando em sujeito discursivo aluno, assim o é, pela capacidade de assumir-se discursivamente nos mais diversos espaços de interação, inclusive dentro da sala de aula (mais um espaço de discursivização do sujeito), a qual é cenário para as cenas da sala de aula (sem querer ser redundante). É um teatro mágico onde as interações acontecem porque sujeitos discursivos ali estão para dar vida à ela.

A empiria nos faz sujeitos capazes de sermos vistos, sentidos e ouvidos; a capacidade de discursivizar e de nos posicionar socialmente nos espaços de interação, nos faz discursivos. Somos, neste tempo, pós-modernos, fragmentados, compostos não de uma única, mas de várias identidades móveis e variáveis. (HALL, 1997).

No espaço da sala de aula, podemos nos relacionar internacionalmente, quando assumimos a posição sujeito de professor ou de aluno, sendo ainda, sujeitos discursivos. Podemos também sermos sujeitos da relação interativa, seja ela, com o livro didático ou com os recursos tecnológicos, como mostramos nos resultados da nossa pesquisa.

Portanto, a preferenciação, principalmente do sujeito discursivo aluno, é pela interação face a face e não pela interação no AVA, através dos gêneros digitais discursivos, o que reforça a nossa percepção pela fragilidade no uso dessas ferramentas, que podem se figurar em territórios de discursivização. A fragilidade dos gêneros digitais discursivos que estudamos, uma vez que as comunidades de práticas (WENGER, 1998) e a permanência do sujeito aluno dentro do ambiente são deficientes. Acreditamos, portanto, que não é o bastante, o aluno ter o acesso aos conteúdos e realizar as tarefas propostas no AVA, mas sim, ser capaz de entender que os gêneros digitais discursivos são territórios de discursivização e que podem fazer parte do seu dia-a-dia escolar. 


\title{
APPROACHES AND REMOVALS BY THE EJA EAD STUDENT IN DISCURSIVE DIGITAL GENDER AS SPACE FOR INTERACTION
}

\begin{abstract}
We understand the classroom and online classroom as interactive spaces for the subject's discursivizations. This excerpt has the general objective of mapping and categorizing discursive behaviors of a group of high school students from Sesi Unidade Sudoeste, of the distance learning mode, in order to visualize actions and reactions that are linked to the work of each and every student, as well as those that materialize specificities of distance learning. Specifically, we intend to find evidence of student interaction in the didactic interaction event in the distance learning classroom. It is justified that the theme addressed here is extremely relevant since we note the emergence of a discursive subject, coming from an industrial context and that permeates the walls of the company for its intellectual training in the classroom, which thus enable the literacies of this subject, through technological tools available and developed in contemporary times and which are strongly present in the different contexts of society. The research is mainly based on the writings of Coscarelli (2002), Modl (2015a) and Paiva (2010). The methodology is qualitative, in ethnographic terms. The procedures are entrance and observation in the VLE and the subjects are the students of the High School YAE DE of Sesi, locus of the research. The results show the distance of the subjects towards what we call digital discursive genres as a space of discrusivization within the VLE.
\end{abstract}

PALAVRAS-CHAVE: Distance Education; Digital Discursive Genres; Interaction.

\section{REFERÊNCIAS}

AMARAL, Márcia Silva. Identidade de Gênero e $(m)$ representações sociais de uma cultura escolar local: apontamentos discursivos e provocações para a agenda do professor. Orientadora: Fernanda de Castro Modl. 2017. 185 f. Dissertação (Mestrado em Letras: Cultura Educação e Linguagens) - Departamento de Estudos Linguísticos e Literários, Universidade Estadual do Sudoeste da Bahia, Vitória da Conquista, 2017.

ASSUNÇÃO, Emerson Tadeu Cotrim. Os letramentos acadêmico e do professor e (m) gestos formativos: a disciplina Seminário Interdisciplinar de Pesquisa (SIP) como locus de investigação.

Orientadora: Fernanda de Castro Modl. 2016. 260 f. Dissertação (Mestrado em Letras: Cultura Educação e Linguagens) - Departamento de Estudos Linguísticos e Literários, Universidade Estadual do Sudoeste da Bahia, Vitória da Conquista, 2016.

BRAGA, J. Comunidades autônomas de aprendizagem on-line na perspectiva da complexidade. Orientadora: Vera Lúcia Menezes de Oliveira e Paiva. 2007. 207 f. Tese (Doutorado em Linguística Aplicada) - Faculdade de Letras, Universidade Federal de Minas Gerais, Belo Horizonte, 2007.

BRUNER, J. Pedagogia Cultural. In: BRUNER, Jerome. Cultura da educação. Lisboa, Portugal: Edições 70, 1996, p.71-95.

COELHO, Fernanda de Castro Batista. Construção identitária e $(m)$ comportamentos na sala de aula: o agenciamento da palavra em dois grupos (um alemão e um brasileiro). 226f. Tese (Doutorado em Letras) - Pontifícia Universidade Católica de Minas Gerais, Belo Horizonte, 2011.

COSCARELLI, C.V. Entre textos e hipertextos. In: Coscarelli C.V. (Org.). Novas tecnologias, novos textos, novas formas de pensar. Belo Horizonte, MG: Autêntica, 2002. p. 65-84.

COSCARELLI, C.V. RIBEIRO, A. E.. Glossário Ceale. Centro Federal de Educação Tecnológica de Minas Gerais-CEFET-MG/Departamento de Linguagem e Tecnologia, Universidade Federal de Minas Gerais-UFMG/Faculdade de Letras, s.d. Disponível em: http://www.ceale.fae.ufmg.br/app/webroot/glossarioceale/verbetes/letramento-digital. Acesso em 12.set.2017

COSTA VAL, Maria da Graça. Texto, textualidade e textualização. In: Ceccantini, J.L. 
Tápias; Pereira, Rony F.; Zanchetta Jr., Juvenal. Pedagogia Cidadã: cadernos de formação: Língua Portuguesa. v. 1. São Paulo: UNESP, Pró-Reitoria de Graduação, 2004. p. 113-128. Disponível no Teleduc.

ERICKSON, Frederick. Prefácio. In COX, Maria Inês Pagliarini; ASSIS-PETERSON, Ana Antônia de. Cenas da Sala de Aula. $1^{a}$ Reimpressão - Campinas, SP: Mercado das Letras, 2003. p. 9-17.

FIEB - Federação das Indústrias do Estado da Bahia. Guia de educação do Sesi Babia. 2017. Disponível em: http://sis.fieb.org.br/fieb/sgm/uploads/Arquivos/A_ce484f31-12f54ba2-aba8-f4ecc56a7674.pdf. Acesso em 06.jun.2017

FLICK, Uwe. Introdução à pesquisa qualitativa. Tradução Joice Elias Costa. $3^{a}$ Ed. Porto Alegre: Artimed, 2009.

FLICK, Uwe. Qualidade na pesquisa qualitativa. Tradução Roberto Cataldo Costa. Porto Alegre. Artimed. 2009b.

KERBRAT-ORECCHIONI, Catherine. Análise da conversação: princípios e métodos. Tradução: Carlos Piovezani Filho. São Paulo: Parábola, 2006

LEMOS, A. Coisas. In: Correio do Povo, Caderno de Sábado, Porto Alegre, 26 de março de 2016.

LÉVY, P. As Tecnologias da Inteligência - o futuro do pensamento na era da informática, Rio de Janeiro: Editora 34, (1 a ed 1990), 1993

MAGNANI, José Guilherme Cantor. A Etnografia como prática e experiência. In: Horižontes Antropológicos, Porto Alegre, ano 15, n. 32, jul/dez. 2009, p.129-156.

MATENCIO, Maria de Lourdes Meirelles. Por uma tipologia da interação em sala de aula. In: MATENCIO, Maria de Lourdes Meirelles. Estudos da lingua e aula de lingua materna: uma abordagem processual da interação professor/alunos. Campinas, SP: Mercado das Letras, 2001. P 99-136.

PAIVA. V. L. M. O. Ambientes virtuais de aprendizagem. In: Educação em Revista, Belo Horizonte, v. 26, n. 30 p. 353-370, dez, 2010

PRIMO, Alex. Interação mútua e reativa: uma proposta de estudo. Revista da Famecos, n. 12, p. 81-92, jun. 2000.

ROCHA, Vilmar do Nascimento; LIMA, Osvaldo Mota Idiomas para a indústria: inglês básico e conversação. In: Seminário de Boas Práticas da Rede Sesi de Educação: projetos premiados em 2015/2016. Salvador. Biblioteca Sesi -Rede Fieb. p.12-21, 2017.

ROJO, Roxane. Entre Plataformas, Odas e Protótipos: Novos Multiletramentos em Tempo de Web 2. In: The ESPecialist: Descrição, Ensino e Aprendizagem, Vol. 38 No. 1 jan-jul 2017. Disponível em: <https://revistas.pucsp.br/index.php/esp/article/view/32219/23261>. Acesso em 16.set.2017.

SANTAELLA, Lucia. A aprendizagem ubíqua na educação aberta. In: Revista Tempo e Espaços em Educação. Sergipe, vol. 7, n. 14, set/dez 2014. Disponível em: https://seer.ufs.br/index.php/revtee/article/view/3446/3010. Acesso em 17.10.2017.

SILVA, L. O. Ambientes Virtuais de Aprendizagem - AVAS. In: SILVA, L. O. Estágio supervisionado com uso de ambientes virtuais: possibilidades colaborativas. 2013. $192 \mathrm{f}$. Tese (Doutorado em Linguística Aplicada) - Universidade Federal de Minas Gerais, Belo Horizonte, 2013. 
SOARES, Claudia Vivien Carvalho de Oliveira. Construção de sentidos em ambientes virtuais de aprendizagem: os fóruns de discussão do Curso Letras Libras - Polo Bahia. Orientadora: Elizabeth Reis Teixeira. 2011. 150 f. Tese (Doutorado em Letras e Linguística) - Instituto de Letras, Universidade Federal da Bahia, Salvador, 2011.

SOARES, Claudia Vivien Carvalho de Oliveira. O ambiente virtual de aprendizagem como prática pedagógica no contexto da educação de surdos. In: Fólio - Revista das Letras. Vitória da Conquista, jan-jun/2014, vol. 6, no 1, p.65-79.

SOUZA, V. V. S. Dinamicidade e adaptabilidade em comunidades virtuais de aprendizagem: uma textografia à luz do paradigma da complexidade. Orientadora: Vera Lúcia Menezes de Oliveira e Paiva. 2011. 256 f. Tese (Doutorado em Linguística Aplicada) - Universidade Federal de Minas Gerais, Belo Horizonte, 2011.

WENGER, Etienne. Communities of practice: learning, meaning and identity. Cambridge: Cambridge University Press, 1998

Recebido em: 15/11/2020.

Aprovado em: 29/12/2020. 